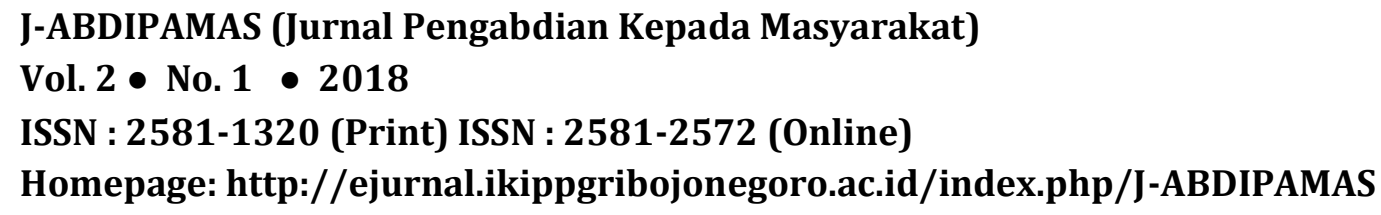

ISSN : 2581-1320 (Print) ISSN : 2581-2572 (Online)

Homepage: http://ejurnal.ikippgribojonegoro.ac.id/index.php/J-ABDIPAMAS

\title{
OPTIMASI PENGGUNAAN SMARTPHONE BAGI MASYARAKAT PERUMAHAN GRIYA PRATAMA
}

\author{
Andi Supriadi Chan ${ }^{1}$, Nurul Azwanti ${ }^{2}$ \\ ${ }^{1}$ Universitas Putera Batam. Email: chakadoang@gmail.com \\ 2 Universitas Putera Batam. Email: Nurulazw@rocketmail.com
}

\begin{abstract}
The development of smartphones and the internet if not accompanied by sufficient knowledge can lead to difficulties in utilizing the technology, with the existence of smartphone smartphone optimization training for residential griya pratama community can help in the use of smartphones and the internet, so as to bring a new knowledge for the community itself in utilizing the development of technology, especially the use of smartphones and internet.banyaknya smartphone users from the early age to adulthood can not be separated from using smartphones for everyday needs. karena lack of knowledge and education about the use of smartphones, but the smartphone was created to have a much more sophisticated function than the functionality of mobile phones in general, so with the guidance in the optimization of the use of smartphones for residential community griya pratama to help the community on the housing for optimal use of smartphones owned for everyday needs, such as to assist in making schoolwork, looking for references and more. And for the purposes of housewives can also develop talent or to entrepreneurship, can to sell online by using smartphones and others, so many things that can be done by the community in utilizing smartphones in everyday life.
\end{abstract}

Keywords: Smartphone, internet, optimization, Community, technology

\begin{abstract}
ABSTRAK
Perkembangan smartphone dan internet ini bila tidak diiringi dengan pengetahuan yang cukup dapat mengakibatkan kesulitan dalam memanfaatkan teknologi tersebut,dengan adanya pelatihan optimasi penggunan smartphone bagi masyarakat perumahan griya pratama ini dapat membantu dalam penggunaan smartphone dan internet,sehingga dapat memunculkan suatu pengetahuan baru bagi masyarakat itu sendiri dalam memanfaatkan perkembangan teknologi,khususnya penggunaan smartphone dan internet.banyaknya pengguna smartphone baik dari usia dini sampai dengan usia dewasa tidak lepas dari menggunakan smartphone untuk kebutuhan sehari-hari.karena kurangnya pengetahuan dan pendidikan tentang penggunaan smartphone,padahal smartphone diciptakan memiliki fungsi jauh lebih canggih daripada fungsi handphone pada umumnya,sehingga dengan adanya pembinaan dalam optimasi penggunaan smartphone bagi masyarakat perumahan griya pratama membantu masyarakat pada perumahan tersebut agar optimal dalam penggunaan smartphone yang dimiliki untuk kebutuhan sehari-hari, seperti untuk membantu dalam membuat tugas sekolah, mencari referensi dan lainnya. Dan untuk keperluan ibu rumah tangga juga bisa mengembangkan bakat ataupun untuk berwirausaha, bisa untuk berjualan online dengan menggunakan smartphone dan lain-lainya, sehingga banyak hal yang bisa dilakukan oleh masyarakat dalam memanfaatkan smartphone dalam kehidupan sehari-hari.
\end{abstract}

Kata Kunci: Smartphone, internet, Optimasi, masyarakat, teknologi 


\section{PENDAHULUAN}

Pemanfaatan dan pemahaman tentang smartphone secara baik dan benar dapat meningkatkan wawasan ,menambah pendidikan serta mampu menaikan taraf hidup masyarakat.serta dapat menambah pengetahuan bagi generasi muda agar dapat menjadi bekal dalam menempuh pendidikan mereka,hal itu dikarenakan sekolah sekarang sudah memberlakukan tugas-tugas dengan menggunakan komputer dan mencari ilmu tambahan lainnya melalui internet (Gifary \& Kurnia, 2014).

Berdasarkan dari wawancara beberapa peserta pengabdi pada Masyarakat Perumahan Griya Pratama,Penggunaan Smartphone sudah sering digunakan oleh masyarakat tersebut, akan tetapi belum bisa memanfaatkan penggunaannya dengan baik dan benar. Maka dari itu pengabdi bertujuan memberikan pembinaan pada masyarakat Perumahan Griya Pratama dengan harapan Masyarakat pada perumahan tersebut bisa lebih memahami dan memaksimalkan penggunaan smartphone dan internet.

Di perumahan griya pratama juga banyak dihui oleh para pelajar dari SD sampai dengan SMA, hampir seluruh pelajar tersebut memiliki smartphone tetapi mereka sendiri tidak mengerti dan paham dalam pemanfaatan dalam menggunakannya, kebanyakan mereka menggunakan hanya sebagai media bertukar pesan, tetapi sangat jarang digunakan untuk dalam dunia pendidikan.padahal smartphone diciptakan untuk menjadikan penggunanya sebagai smart people (Dewanti \& Widada, 2016). Bisa juga dijadikan sebagai gudang ilmu pendidikan bagi pelajar, tetapi mereka tidak mampu memanfaatkan smartphone yang mereka miliki sehingga hal tersebut menjadi mubazir.

Para orang tua yang berada di perumahan griya pratama juga kebanyakan hanya menggunakan smartphone mereka untuk berkomunikasi juga, padahal mereka bisa berwirausaha dengan menggunakan smartphone mereka,baik itu online shop yang lagi trend saat ini maupun kuliner dan lainnya.maka dari itu sangat perlu dilakukan pembinaan bagi masyarakat perumahan griya pratama dalam mengoptimalkan penggunaan smartphone sehingga perumahan ini dapat menjadi perumahan smart people yang dapat memanfaatkan smartphone di era globalisasi seperti saat ini.

Dalam melakukan kegiatan pembinaan ini ada beberapa permasalahan yang dapat dirumuskan, diantaranya adalah tentang sejauh mana pengetahuan dan kemampuan masyarakat Perumahan Griya Pratama tentang penggunaan smartphone dan internet, kemudian pemanfaatan smartphone dan internet sebagai wawasan tambahan yang bisa diterapkan di sekolah dan di lingkungan perumahan serta menggunakan smartphone dan internet secara maksimal pada perumahan griya pratama kota batam. Sehingga masyarakat tersebut dapat menjadi lebih bijak dan lebih baik dalam memanfaatkan smartphone yang mereka miliki.

Tujuan yang diharapkan dari kegiatan ini adalah untuk memberi pengenalan dan pemahaman serta pembinaan tentang optimasi penggunaan smartphone dan internet pada masyarakat Perumahan Griya Pratama agar mampu memaksimalkan pengetahuan tersebut dengan baik dan dalam kehidupan sehari-hari 


\section{METODE PELAKSANAAN}

Metode pelaksanaan pada program pengabdian masyarakat ini dengan metode pelatihan secara langsung kepada masyarakat perumahan griya pratama batu aji. Adapun tahapan pelaksanaan program yaitu sebagai berikut :

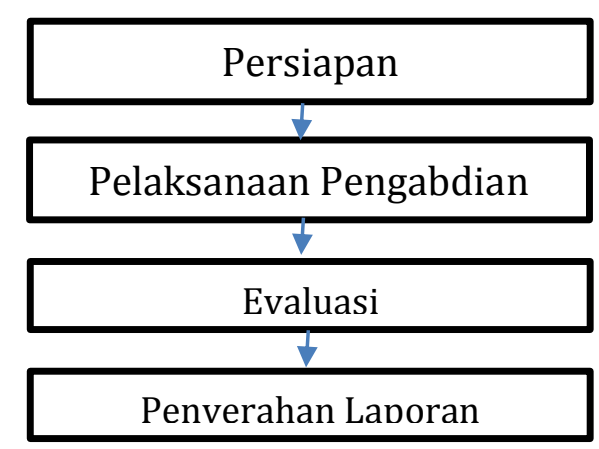

Gambar 1.Diagram Alur Kegiatan

1. Persiapan

Kegiatan yang akan dilakukan pada tahap persiapan yaitu :

a. Survei tempat pelaksanaan kegiatan

b. Pembuatan proposal dan penyelesaian administrasi untuk program pengabdian masyarakat.

c. Penyiapan alat dan bahan untuk pembuatan media pembelajaran seperti laptop, LCD Proyektor dan Materi.

2. Pelaksanaan pengabdian

Kegiatan pengabdian akan dilaksanakan setelah semua persiapan sudah selesai dilakukan. Kegiatan akan dilaksanakan di Sekolah Dasar. Dalam pelaksanaanya pemateri memberikan latihan serta cara menggunakan geoboard dalam mata pelajaran matematika dalam materi keliling dan luas bangun datar segiempat dan segitiga.

3. Evaluasi

Evaluasi ini bertujuan untuk melihat perkembangan program yang dilaksanakan, dengan mengadakan test lisan sehingga program pengabdian yang dilakukan benar-benar efektif dan maksimal

4. Pembuatan Laporan

Pembuatan laporan disesuaikan dengan hasil yang telah dicapai selama melakukan pelatihan optimasi penggunaan smartphone pada masyarakat griya pratama 


\section{HASIL DAN PEMBAHASAN}

Dengan adanya program kegiatan pengabdian yang diselenggarakan oleh pihak kampus Universitas Putera Batam, dengan lokasi pengabdian di Perumahan Griya Pratama ini, ada beberapa hal yang akan diperoleh salah satunya adalah Dapat membangun hubungan dan kerjasama yang baik antara pihak Universistas Putera Batam dengan masyarakat umum khususnya di Perumahan Griya Pratama sehingga dengan pengadaan pembinaan ini Dapat menambah ilmu, pengalaman dan pelajaran bagi peserta binaan, dari yang tidak tahu menjadi tahu dan dari yang kurang memahami tentang cara MengOptimasikan penggunaan Smartphone bisa menjadi lebih paham dan mendalaminya. Serta mengembangkan serta berbagi pengalaman tentang artinya pendidikan dan pelajaran bagi yang tidak berkeinginan melanjutkan pendidikannya.

Setiap peserta diberikan test dan mendapatkan nilai sesuai dengan yang diharapkan. Berikut tabel nilai hasil test lisan yang dilakukan oleh Pembina :

Tabel 4.1 Hasil Nilai Belajar Siswa

\begin{tabular}{lll}
\hline No & Nama & Nilai \\
\hline 1 & Sawiyanti & 70 \\
\hline 2 & Ayu Soraya & 65 \\
\hline 3 & Galang Purnama Saputra & 60 \\
\hline 4 & Gyo Akmal & 75 \\
\hline 5 & Dewi Puji Jayanti & 85 \\
\hline 6 & Meri Kartika & 60 \\
\hline 7 & M. Arka Saputra & 70 \\
\hline 8 & Ami Nur Safitri & 75 \\
\hline 9 & Nurmala & 65 \\
\hline 10 & Fauzal Abdullah & 70 \\
\hline
\end{tabular}

\section{SIMPULAN}

Berdasarkan hasil kegiatan Pengabdian kepada masyarakat yang telah di laksanakan, maka dapat dibuat kesimpulan diantaranya:

1. pengabdian ini memberikan pelatihan materi berupa optimasi penggunaan smartphone pada perumahan griya pratama batu aji mendapatkan respon positif dari masyarakat .

2. masyarakat yang menjadi peserta pelatihan merasakan dampak bertambahnya pengetahuan dengan bukti dapat menjawab beberapa pertanyaan yang diberikan, sehingga pengabdian ini berjalan dengan sukses.

3. Peserta pelatihan cukup aktif ketika praktek dalam memanfaatkan smartphone mereka seperti untuk melakukan transaksi secara online 


\section{DAFTAR RUJUKAN}

Dewanti, T. C., \& Widada, T. (2016). Hubungan Keterampilan Sosial dan Penggunaan Gadget Smartphone dengan Prestasi Belajar Siswa SMA Negeri 9 Malang. Jurnal Kajian Bimbingan Dan Konseling, 1(3), 126-131.

Sharen Gifary dan Iis Kurnia N. (2015). Intensitas Penggunaan Smartphone Terhadap Perilaku Komunikasi. jurnal Sosioteknologi, Vol. 14, No. 2. 170-178

http://www.cnnindonesia.com/teknologi/20160222155236-213-112610/penggunainternet-indonesia-tumbuh-berkat-smartphone/

http://www.isigood.com/wawasan/tips-menjadi-pengguna-smartphone-yang-bijak/ 